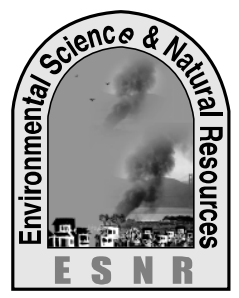

J. Environ. Sci. \& Natural Resources, 5(2): 239 - 244, 2012

ISSN 1999-7361

\title{
Public Awareness about Disposal of Solid Waste and its Impact: A Study in Tangail Pourashava, Tangail
}

\author{
B. C. Sarker, S. K. Sarker, M. S. Islam and S. Sharmin
}

Department of Environmental Science and Resource Management

Mawlana Bhashani Science and Technology University, Santosh, Tangail-1902, Bangladesh

\begin{abstract}
The investigation was conducted on public awareness about disposal of solid waste and its impact in Thanapara, Beparipara and Kagmari of Tangail Pourashava. Data collected through questionnaire interview from local residents, self-observation and secondary sources. The investigation was conducted among three major infected areas by selecting normal dustbin and open area during the different period from August to September 2011. In the study, total 100 respondents are interviewed and the result shows that waste are dumped here three times a day. Most of the respondents demand for wrong site selection and improper maintenance causing bad odor, diarrheea, skin diseases, aesthetic problem etc. It was also found that the main sources of waste materials generation were the urban dwellers and most of the waste is dumped by metropolis. Some local people also dump their waste in the area. The study shows that the service holders, student respondents have better idea about the effects of dumping solid wastes at open sights than the other respondents.
\end{abstract}

Key word: Awareness, Disposal, Health problem, Management, Waste

\section{Introduction}

Any matter, whether liquid, solid, gaseous, or radioactive, which is discharged, emitted, or deposited in the environment in such volume, constituency or manner as to cause an alteration of the environment. Useless, unwanted or discarded materials and is not free flowing products are solid waste (WHO, 1971). Solid waste is one of the most visible, immediate and serious environmental problems confronting municipal authorities in developing countries like Bangladesh (Rahman et al., 2000). Most of the municipal waste materials in Bangladesh collected is dumped on open wasteland or low-lying areas even near creeks, forests, rivers, ponds and other ecological sensitive regions in a more or less uncontrolled manner, such inadequate waste disposal creates serious environmental problems that affect health of humans and animals and cause serious economic and other welfare losses. This does not meet the norms of disposal specified in the municipal solid waste rules (Sahu, 2007). Due to improper management and lack of public awareness, a major part of Tangail city is largely polluted and create health sufferings of general people. The environmental degradation as well as health impact of people caused by inadequate disposal of waste can be expressed by the contamination of surface and ground water through direct waste contacts or leachate, air pollution by burning of wastes, spreading of diseases by different vectors like birds, insects and rodents, or uncontrolled release of methane by anaerobic decomposition of waste. Throughout the cities, it is the urban poor that suffer most from the life threatening conditions deriving from deficient waste management (Kungskulniti, 1990). At the present situation, it is very much essential to grow awareness among the people of Bangladesh about the problems associated with the environment such as open dumping of solid wastes and its effect, water pollution etc. in order to conserve or protect the environment. Considering the above views in mind, the present study was undertaken with the objective to determine the status of public awareness about disposal of solid waste and its impact: a study at Thanapara, Beparipara and Kagmari in Tangail Pourashava.

\section{Materials \& methods}

The study was carried out to examine the public awareness about Impact of solid waste disposal and its management system on Thanapara, Beparipara and Kagmari region in Tangail Pourashava where there are 288 households in Beparipara, 772 households in Thana Para and 479 in Kagmari respectively. One hundred people were selected through simple random sampling technique. Data were collected through structured and semi-structured questionnaire and interview methods. The questionnaire containing 45 questions (e.g. idea about solid waste, health impacts of solid waste, environmental pollution from improper management of solid waste, problems facing from dumping site etc.) was developed to obtain the relevant information. Data were collected during the period from August to September 2011. The statistical 
measures such as number and percent distribution were used for describing the variables of the study. Data are coded, tabulated and analyze by using statistical method of SPSS (Statistical Package for Social Science) and Microsoft Excel.

\section{ResultS and discussion}

Among the 100 respondents, $45 \%$ of the respondents were between $18-25$ years, $24 \%$ people were between $26-35$ years, $26 \%$ respondents were between $36-50$ years, $5 \%$ respondents were above 50 years of aged. Here, $55 \%$ respondents are male and $45 \%$ respondents are female. Table 1 shows the Age range and sex of the respondents and Figure 1 shows the sex ratio of the respondents.

Table 1. Age range and sex of the respondents

\begin{tabular}{|c|c|c|c|}
\hline \multirow{2}{*}{ Age } & \multicolumn{2}{|c|}{ Sex (frequency) } & \multirow{2}{*}{ Percentage (on age limit) } \\
\cline { 2 - 3 } & Male & Female & 45.0 \\
\hline $18-25$ & 24 & 21 & 24.0 \\
\hline $26-35$ & 11 & 13 & 26.0 \\
\hline $36-50$ & 17 & 09 & 5.0 \\
\hline$>50$ & 03 & 02 & 100.0 \\
\hline Total & 55 & 45 & \\
\hline
\end{tabular}

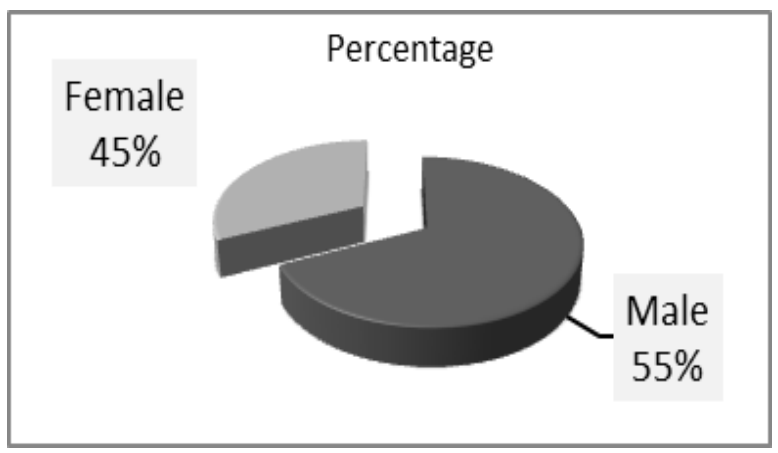

Fig. 1. Sex ratio of the respondents.

Figure 1 shows that most of the respondents were male $(55 \%)$ and a major portion $(24 \%)$ of male respondents range between $18-25$ years. Data showing in figure 2 shows that $24.0 \%$ respondents are illiterate, $31.0 \%$ respondents are range from class $\mathrm{i}-\mathrm{v}, 19 \%$ of the respondents are SSC passed, 17\% are HSC passed and the 09\% of respondents are graduate (Figure 2). We can hardly say that the educational status of most of the respondents is not satisfactory. Therefore, majority of them are not aware enough about impacts of miss management and careless dumping of solid waste.

We have classified the total respondents into five categories and the maximum respondents $(43 \%)$ were students. Among the other respondents, $17 \%$ was housewife, $07 \%$ was day labor and $15 \%$ was Rickshaw puller and rest of the $18 \%$ were service holder. Figure 3 shows occupation types of the respondents. 


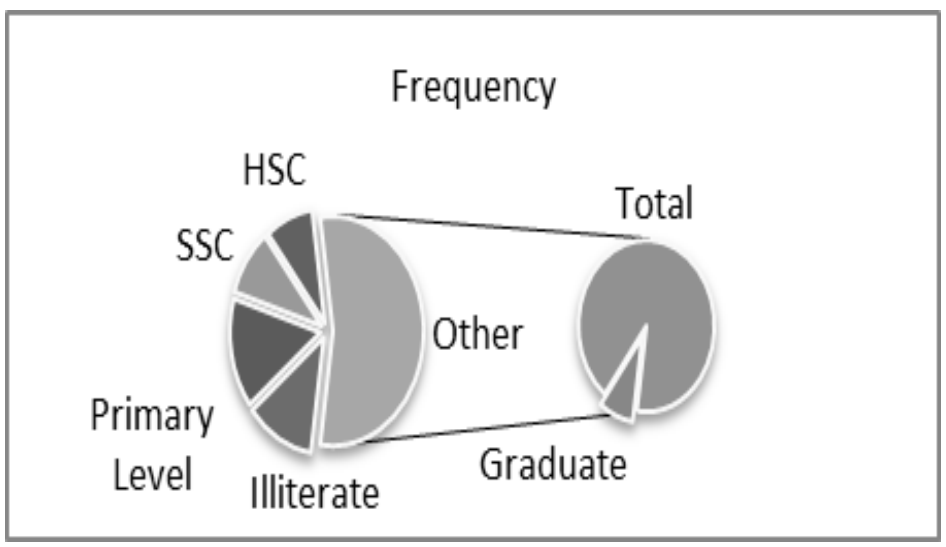

Fig.2: Educational qualification of the respondents

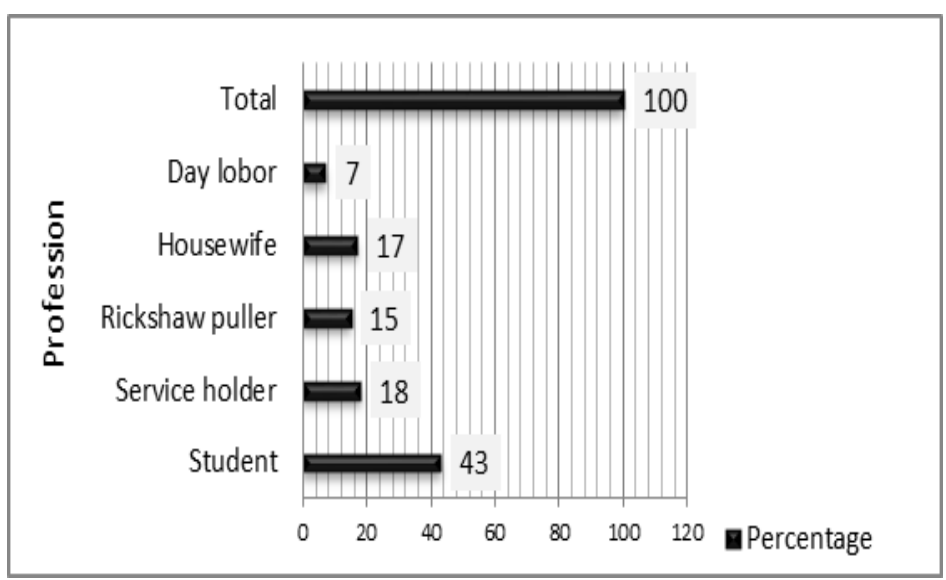

Fig. 3: Occupation type of the respondents

Data of figure 4 (below) shows, about $89 \%$ of the total respondents has more or less idea about waste. However, more than half of respondents (53\%) does not have idea about hazards of solid wastes such as offensive odor, health problem, aesthetic problem, etc. and $47 \%$ has no idea about how solid wastes are causing problem or polluting our environment. The figure 3 also indicates that, about $56 \%$ of the people are aware to dump their waste in nearby Dustbin so that it does not create any problem. Only near about 37\% people are aware about the NGO's participation regarding public health, $58 \%$ has more or less idea about proper and safe waste management procedure but more than half of the respondents are not aware about the problem and think that, governments' participation relating the issue is very poor (88\%). Nevertheless, majority (87\%) of respondents agreed that, their individual participation was very much necessary to maintain the disposal system in a safe and appropriate way whereas 13\% does not have any headache regarding associated problems regarding solid waste. 


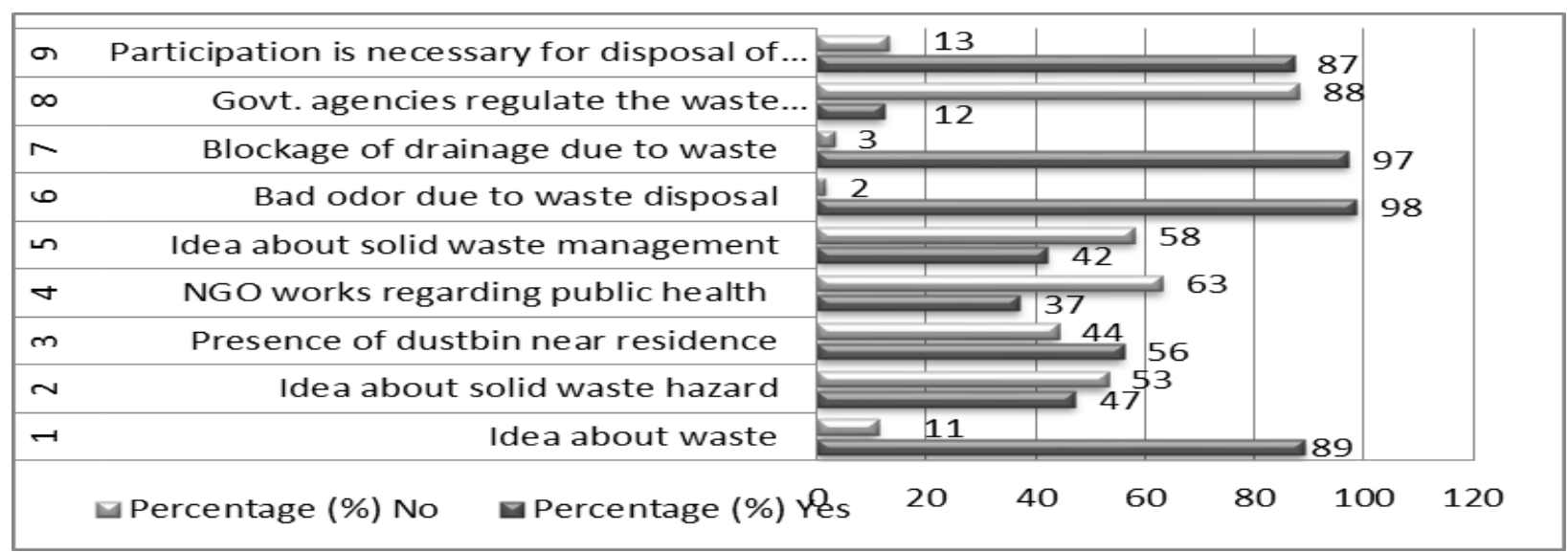

Fig. 4: Perception about dumping of solid waste

Figure 5 shows that about $37 \%$ of respondents more or less practice of solid waste management and $63 \%$ do not.

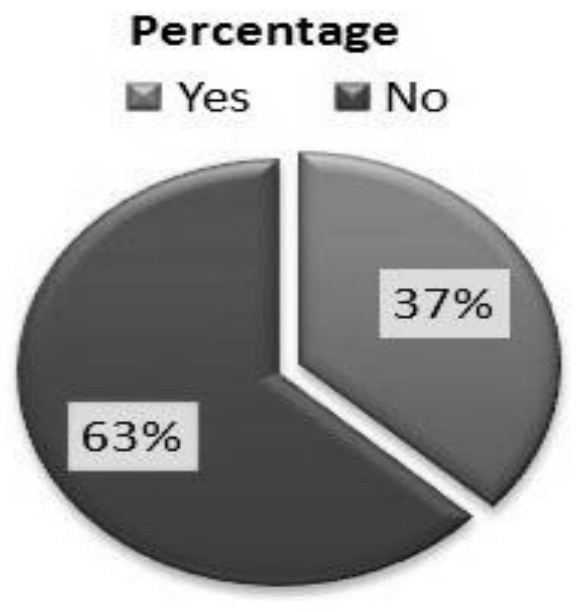

Fig. 5: practice of solid waste management

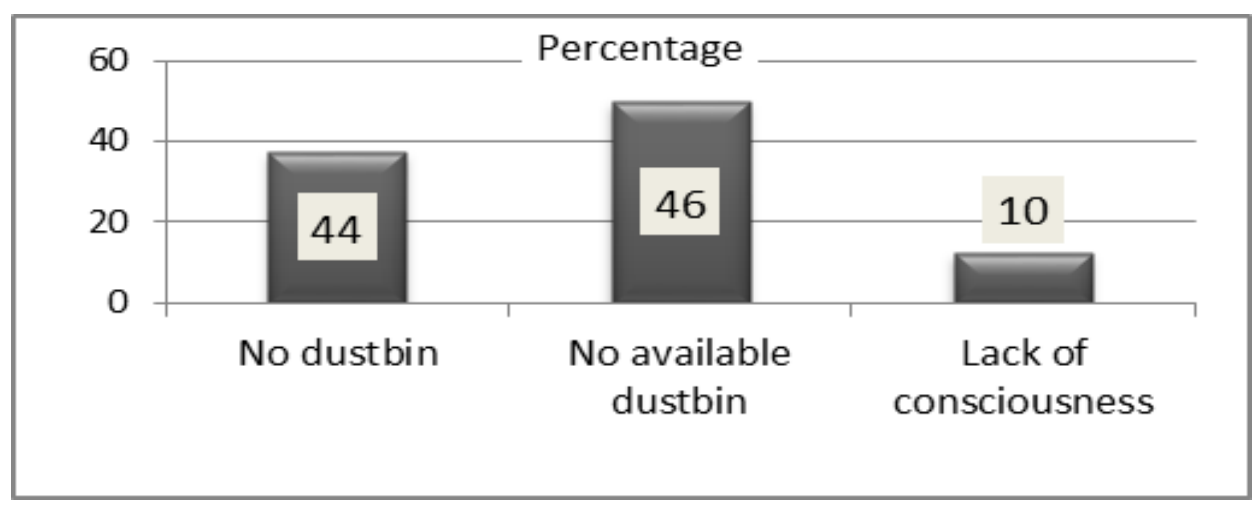

Fig. 6: Reason of open dumping of household wastes

Hence (figure 6), out of $63 \%$ of respondents $44 \%$ said that, $46 \%$ said they do that, as there are not sufficient number of dustbins and $10 \%$ of the respondents accused their unconsciousness 


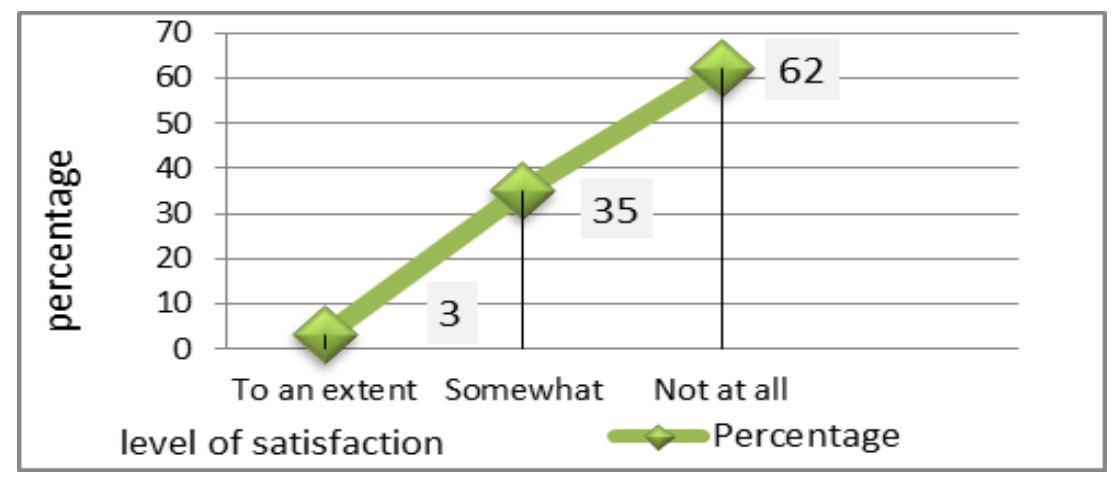

Fig. 7: Satisfaction level of present solid waste management system.

Figure 7 shows that, $3 \%$ respondents have negligible satisfaction, $35 \%$ is moderately satisfied and majority $(62 \%)$ are not satisfied at all on present solid waste management system of Tangail Pourashava.

The figure 8 shows Improper waste management creates specific problems to respective ones. To someone bad odor (9\%), Mosquito generation (11\%), blockage of drainage (8\%) and Majority of the respondents $(72 \%)$ face all of the above-mentioned waste related problems respectively. From the view of the respondents, they just want to lead a safe and healthy life. For owing these majority of the respondents $(65 \%)$ assents the essence of having environmental education of all classes of people, whereas out of the rest 35\% respondents $13 \%$ and $22 \%$ are somewhat agree and neutral respectively (figure 9).

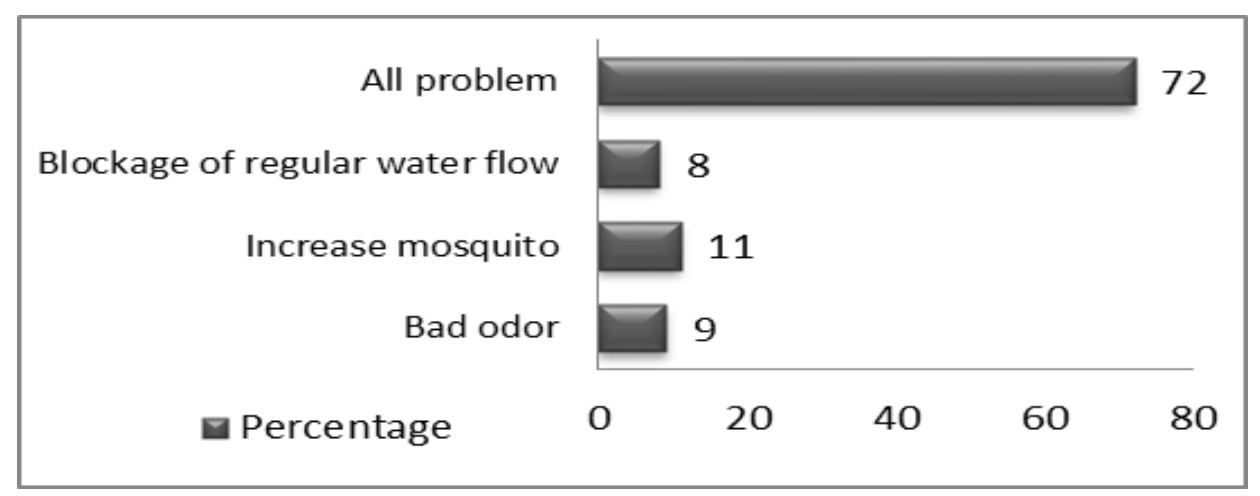

Fig. 8: Problem arises for improper dumping of waste

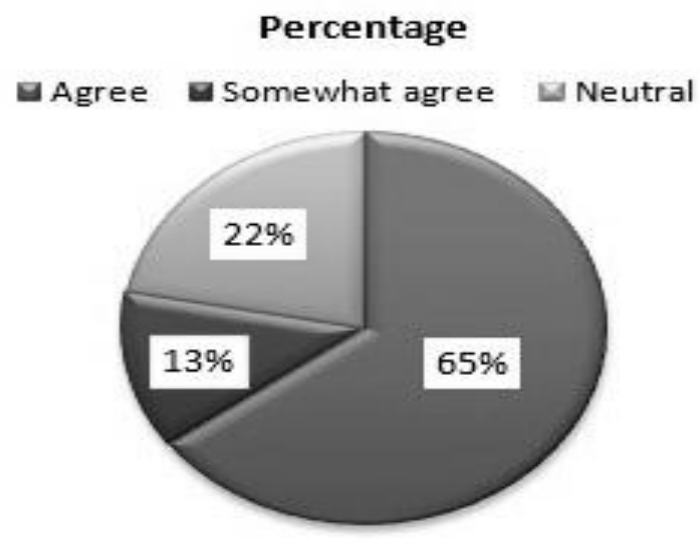

Fig. 9: Essence of Environmental education 


\section{Conclusion}

The study showed that the extent of general concept of environmental awareness among the local people of the study areas wes somewhat satisfactory although they had average ideas about solid waste, effect of solid wastes, solid waste management, problems associated with solid waste management, etc. This study also showed that there is a significant difference in awareness among various level of occupation. The study found that the student, service holder respondents is more aware about the problem, than their counterparts Rickshaw puller and others. A large number of respondents suggested that it is necessary to improve present solid waste management system of Tangail Pourashava and to change the place for dumping municipal solid waste from nearside of Kagmari (Louhojong River) Bridge to other place where effects of dumping solid waste will be negligible. A large number of respondents suggest that, management of disposal facility should be increased to a satisfactory level and awareness must be developed among all classes of people so that the negative consequences of wastes can be reduced at a large extent.

\section{Recommendation}

- Publicity of waste management practices through distributing of leaflets, posters and mass media support,

- All the parties' (i.e. government, households, service holders, students, day labor, businessperson, etc.) spontaneous participation and involvement should be ensured to manage and dispose solid wastes properly in order to maintain clean and healthy environment.

\section{References}

Kungskulniti, N. 1990. Public health aspects of a solid waste scavenger community in Thailand. Waste Management and Research, 8(2):167-170.

Rahman, M. M and Ali M. A. 2000. Waste management and environmental pollution in Bangladwsh. Paper presented at the Intl Conf. Bangladesh Environ., ICBEN, BUET, Dhaka, Bangladesh, 14-15 January 2000.

Sahu, A. K. 2007. Present Scenario of Municipal Solid Waste (MSW) Dumping Grounds in India, Proceedings of the International Conference on Sustainable Solid Waste Management, Chennai, India, pp: 327333.

World Health Organizaton (WHO), 1971. Safe management of wastes from healthcare activities.Tech.Pep. Ser. No. 484. 